\title{
Regime cambial e mudança estrutural na indústria de transformação brasileira: evidências para o período (1994-2008)
}

\author{
ELIANE ARAÚJO \\ MIGUEL BRUNO \\ DÉBORA PIMENTEL*
}

Exchange rate regime and structural changes in the Brazilian manufacturing industry. This article proposes an analysis of the relationship between exchange rate regime and evolution of the Brazilian manufacturing industry during the period 1980-2008. Its main purpose is to detect the direction of the structural changes imposed by the new form of international insertion consolidated throughout the 1990s. The work also provides new empirical evidence regarding the assumptions of deindustrialization and "Dutch disease", which mark the current debate on the effects of the appreciation of real exchange rate in the Brazilian economy.

Keywords: exchange rate; manufacturing industry; structural changes.

JEL Classification: F31; L16; L17; L25.

\section{INTRODUÇÃO}

Diversos trabalhos empíricos têm procurado detectar os impactos das estratégias nacionais de liberalização econômica sobre as estruturas de produção industrial. Nessa problemática, as mudanças de regimes cambiais, entendidas como o conjunto de regras que governam a definição das taxas de câmbio, têm se constituído em um ponto de partida natural para uma análise robusta das transformações

\footnotetext{
* Respectivamente, Professora adjunta da Universidade Estadual de Maringá. elianedearaujo@yahoo. com.br, Assessor de projetos especias - crescimento e desenvolvimento do IPEA e professor adjunto da UERJ, e-mail: Miguel.bruno@ipea.gov.br, e Mestre em Economia. Escola Nacional de Ciências Estatísticas, ENCE-IBGE, Brasil, e-mail: deboramp@globo.com. Submetido: 23/junho/2010; Aprovado: 28/março/2011.
} 
da indústria, quando o grau de abertura comercial e financeira é significativamente aprofundado. No entanto, diferentemente do que ocorre no âmbito internacional, a literatura econômica para o caso do Brasil ainda carece de estudos sobre os efeitos das taxas de câmbio sobre o comportamento da indústria.

A exceção são os trabalhos de Bresser-Pereira (2008, 2009 e 2010) e Bresser-Pereira e Gala (2007) e Bresser-Perira e Marconi (2008), que, desde o início da década, discutem a relação entre câmbio e crescimento econômico, destacando os riscos da desindustrialização causada pela sobreapreciação da taxa de câmbio real, cuja origem está na política de crescimento com poupança externa e na doença holandesa

Apesar do discurso corrente acerca das características supostas quase sempre positivas de uma economia baseada em serviços, consagrando o uso de expressões tais como "economia do conhecimento", "economia pós-industrial" e "nova economia", a experiência histórica mostra que a indústria ainda é a base do desenvolvimento das nações. Mesmo que nas atuais economias os serviços tenham alcançado posições qualitativa e quantitativamente proeminentes, a indústria continua sendo a principal fornecedora dos insumos fundamentais às atividades terciárias. O deslocamento do emprego industrial pelo emprego terciário não implica necessariamente perda de importância econômica do setor secundário, visto que a geração de valor nos serviços permanece substancialmente dependente da materialização de conceitos, de inovações tecnológicas e das infraestruturas provenientes de processos produtivos industriais. Reforçando essa tendência de subavaliação da relevância da indústria pode-se acrescentar o fato de que inúmeras atividades que outrora eram consideradas tipicamente industriais têm sido reclassificadas e introduzidas no rol dos serviços, tendo-se em vista os benefícios fiscais e organizacionais dos processos de terceirização.

Este artigo propõe uma análise das relações entre regime cambial e o desempenho da indústria de transformação brasileira no período 1980-2008. Seu principal objetivo é detectar o sentido das transformações impostas pela nova forma de inserção internacional consolidada ao longo da década de 1990. O trabalho proporciona novas evidências empíricas quanto às hipóteses de desindustrialização e de "doença holandeza" que marcam o debate atual sobre os efeitos da apreciação real do câmbio numa economia como a brasileira.

Além desta introdução, o texto está estruturado da seguinte maneira: a segunda e terceira seções proporcionam, respectivamente, um balanço da literatura nacional e internacional sobre o tema em foco, destacando os principais estudos e pesquisas já desenvolvidos. Com base em séries de produtividade, estoque de capital fixo, valor adicionado, taxa de utilização da capacidade e taxa efetiva real de câmbio, a quarta seção seleciona três fatos estilizados da evolução contemporânea da indústria, por expressarem, no plano macroeconômico, mutações importantes na configuração deste setor. A quinta seção reúne as evidências sobre a nova estrutura industrial pós-liberalização, explicitando o novo padrão de especialização. $\mathrm{O}$ trabalho é concluído com a sexta seção. 


\section{REVISÃO DA LITERATURA}

A partir da década de 1990 diversas pesquisas têm se dedicado ao estudo das mudanças estruturais ocorridas na indústria brasileira. Entre estas se destaca o trabalho de Bonelli e Gonçalves (1998) que, utilizando dados da United Nations Industrial Development Organization (UNIDO), apontam quatro fases distintas do processo de industrialização no Brasil. A primeira compreende o período entre 1932 e 1962, quando a taxa média de crescimento da indústria foi de $9 \%$ ao ano, com destaque para as profundas mudanças na matriz industrial do país, consequência do processo de substituição de importações a partir dos anos 1950. A segunda é o período entre 1967 e 1973, quando a indústria cresceu a taxas significativas, superiores a $13 \%$ ao ano, incorporando e consolidando setores-chave na indústria brasileira, como o de bens de capitais. A terceira fase, que vai até o fim da década de 1980, é marcada por uma reversão do crescimento da produção industrial, que foi da ordem de $2 \%$ negativo ao ano, além disso, setores como bens intermediários, bens de capital e parte dos bens de consumo duráveis perdem participação no total da indústria. Por fim, a quarta fase, década de 1990, se caracteriza por uma leve recuperação da indústria quando comparada ao desempenho do período precedente, embora ainda muito inferior as trajetórias da primeira e segunda fase do processo de industrialização brasileira.

Buscando uma maior compreensão da década de 1990, Ferraz, Kupfer e Iootty (2004) analisam as transformações ocorridas com a indústria no período. Esta década é marcada por profundas transformações com importantes implicações para a indústria brasileira, destaca os autores. Dentre elas cabe ressaltar as reformas liberalizantes: a desregulamentação da economia, a liberalização do setor externo e a privatização das indústrias de transformação e dos serviços de utilidade pública. Essas reformas combinadas com a estabilização monetária implicaram um ambiente muito mais competitivo para as indústrias nacionais. A âncora cambial, utilizada como instrumento de estabilidade de preços, mantinha o câmbio valorizado, o que associada à política de juros altos e a redução das barreiras à entrada de empresas estrangeiras no país traziam para as empresas nacionais uma situação extremamente adversa. O resultado dessas políticas foi a deterioração da balança comercial brasileira e a entrada de capital estrangeiro para financiar este déficit, o que, por sua vez, elevou a vulnerabilidade externa da economia nacional. Além disso, a década de 1990 foi para a economia brasileira um período de baixo crescimento dos investimentos e do produto interno bruto (PIB), o que contribuiu para agravar a situação das empresas nacionais.

Kupfer (2003) aponta ainda que a liberalização comercial levou a um grau de especialização regressiva das exportações brasileiras, isto é, uma especialização na exportação de produtos de menor valor agregado em detrimento dos produtos mais sofisticados, o contrário ocorrendo no caso das importações. Além disso, houve um processo de modernização das indústrias mediante a simplificação de produtos e processos e outsourcing de insumos, o que por sua vez teria gerado um aumento 
no patamar da produtividade da indústria, mas que, destaca o autor, não seria capaz de gerar estímulos para aumentar de forma sustentada este patamar.

Também Garcia (2004) analisa as mudanças ocorridas na estrutura industrial brasileira em termos das alterações verificadas nas participações das distintas atividades industriais no total da indústria de transformação, tanto em valor da produção industrial como em valor da transformação industrial no intervalo de 1985 a 2000. A autora apresenta um índice de mudança estrutural, seguindo a metodologia da UNIDO, que indica uma significativa mudança estrutural no período estudado. Agregando as indústrias por fatores de especialização competitiva e intensidade tecnológica, a mudança se deu na direção das indústrias intensivas em recursos naturais e em escala, revelando um padrão de especialização competitiva que não se desenvolve na direção de atividades tecnologicamente mais complexas, ao contrário do que ocorre em estruturas industriais de países mais avançados como Estados Unidos, Japão e Coreia do Sul.

A este respeito, Carvalho e Kupfer (2008a), ao analisarem a estrutura industrial brasileira em termos de valor adicionado constatam que a mudança estrutural foi um processo iniciado na primeira metade da década de 1990 e aprofundado nos anos 2000. A especialização consistiu em ganho de peso de alguns setores de menor intensidade tecnológica, que inclusive já respondiam por uma parcela elevada do produto industrial. Com base nesta constatação, os autores buscam compreender os fatores explicativos deste processo e concluem que esta mudança na estrutura da indústria brasileira deriva dos efeitos conjuntos de da falta de dinamismo da demanda doméstica e do processo de abertura comercial.

Com base em uma análise empírica Pereira, (2008) destaca duas conclusões principais. A primeira delas é a existência de uma especialização da indústria brasileira, que vem ocorrendo precocemente e de maneira acelerada. Os baixos níveis de renda per capita a partir dos quais a indústria no Brasil inverteu sua trajetória de diversificação indicam que a expansão do conjunto dos setores industriais estancou antes que a infraestrutura produtiva da economia brasileira tivesse sido completada.

Em Carvalho e Kupfer (2008b) são apresentadas evidências em favor deste argumento, isto é, de que a indústria brasileira vem ficando menos diversificada ao longo do tempo. Segundo os autores, esse processo ocorre de forma intensificada e precoce, o que é evidente quando se compara o nível de renda per capita no qual se encontra o maior grau de diversificação da estrutura produtiva brasileira — US\$ 4.000 - com os valores respectivos para a Austrália e Canadá - entre US\$18.000 e US\$ 20.000, respectivamente - e Estados Unidos - US\$ 22.000. Mesmo quando comparados a países de industrialização mais recente, Taiwan e Coreia — os níveis de renda per capita também são bem maiores do que o do caso brasileiro — US\$ 12.000 e US\$ 8.000, respectivamente.

A segunda conclusão destacada por Pereira (2008) é a mudança na composição da indústria em favor dos setores ligados à produção de commodities, ressaltando o ganho significativo de importância do setor petróleo. Analisando a evolução da balança comercial brasileira mostra que os saldos comerciais com o exterior de- 
pendem de forma crescente dos saldos dos setores não industriais da economia e dos setores menos intensivo em tecnologia da indústria, indicando um "empobrecimento" da pauta exportadora nacional.

Nesse sentido, destaca o autor, a apreciação permanente da taxa de câmbio real está associada a um "aumento relativo" do setor exportador de commodities, de maior produtividade, e a um "encolhimento" do setor manufatureiro. Pois, como demonstrado por ele, as exportações de bens primários têm ampliado sua participação na balança comercial e as importações de bens manufaturados têm crescido relativamente às exportações desse setor. Em consequência, observa-se relativa especialização da pauta de exportações e uma piora na balança comercial de bens manufaturados.

Com base nestas pesquisas é possível constatar uma mudança na trajetória da indústria brasileira, tanto no que se refere à taxa de crescimento da indústria como à mudança em sua estrutura. Assim, além de significativa redução das taxas de crescimento, a indústria ainda concentra-se em produtos de menor componente tecnológico, com destaque para produtos ligados ao setor de commodities.

Ao contrário da literatura nacional, a relação direta entre taxa de câmbio e estrutura industrial tem sido objeto de amplo estudo na literatura internacional. A exceção são os trabalhos de Bresser-Pereira et al., que, desde o início da década, discutem a relação entre câmbio e crescimento econômico, destacando os riscos de desindustrialização provocados por uma tendência persistente de apreciação real do câmbio na economia brasileira. Para Bresser-Pereira, este processo ocorre de forma análoga ao caso holandês levando a indústria brasileira a uma especialização em commodities e produtos de baixo valor agregado.

As pesquisas no âmbito internacional vão no sentido de explorar o papel da taxa de câmbio em determinar o investimento industrial, avaliando os efeitos do nível e da volatilidade da taxa de câmbio sobre a decisão de investimento das firmas, como exemplo citam-se Harchaoui, Tarkhani e Yuen (2005); Nucci e Pozzolo (2001); Worthington (1991); Goldberg (1993); Campa e Goldberg (1995); Campa e Goldberg (1999); Blecker (2005; Byrne e Davis (2002); Darby et al. (1999); Atella, Atzeni e Belvisi (2003). Os resultados dessa literatura focam dois argumentos principais, um deles é o argumento da volatilidade, segundo o qual uma taxa de câmbio estável incentiva as firmas a investirem por possibilitar que elas tenham uma estimativa mais confiável a respeito de seus lucros esperados. Outro é o argumento da desvalorização cambial, defendendo que uma taxa de câmbio desvalorizada pode afetar positivamente os investimentos, por tornar os produtos nacionais mais competitivos no mercado externo.

As contribuições de Bresser-Pereira (2008, 2009 e 2010) destacam-se no plano teórico com a elaboração de uma macroeconomia estruturalista do desenvolvimento, segundo a qual a desindustrialização é causada pela sobreapreciação do câmbio cujas causas principais são a política de crescimento com poupança externa e a doença holandesa.

Bresser-Pereira e Gala (2007) oferecem uma crítica à visão de que as economias em desenvolvimento, em virtude das baixas taxas de poupança que possuem, po- 
dem aceitar déficits em conta-corrente para estimular um maior crescimento econômico, pois a absorção de poupança externa tenderia a complementar a poupança interna, aumentando a poupança total da economia, o investimento e, consequentemente, o crescimento econômico. Os autores ressaltam que em um país que adota a estratégia de crescimento com poupança externa, a primeira consequência é a apreciação da taxa de câmbio. Do lado da oferta, isso implica aumento artificial dos salários, e, em consequência, aumento do consumo e redução da poupança interna. Do lado da demanda, o resultado é a diminuição das oportunidades de investimento lucrativo voltados para a exportação, que reduz o investimento e a poupança interna. Nesse caso, a poupança externa em grande parte substitui ao invés de se constituir em um acréscimo à poupança interna.

Ainda nessa temática, Bresser-Pereira e Nakano (2003) apresentaram evidencias de que a liberalização dos fluxos financeiros internacionais associados a estratégia de crescimento com poupança externa levou muitos países em desenvolvimento a registrarem elevados déficits em conta-corrente e aumento da dívida externa, ignorando a solvência e restrição do limite da dívida. Em termos práticos, isso implicou para esses países sobrevalorização das moedas nacionais e altas taxas de juros, com consequências perversas sobre o crescimento dessas economias.

Já no debate sobre a doença holandesa e a desindustrialização no Brasil, Bresser-Pereira (2008) ressalta que a apreciação cambial decorrente da exportação de recursos naturais com base em rendas econômicas inviabiliza a produção de bens comercializáveis, com destaque para os manufaturados que possuem maior potencial de inovação tecnológica e ganhos de produtividade. O espaço dos bens manufaturados é ocupado pelo setor de recursos naturais e bens não comercializáveis, de forma que o capital e o trabalho são deslocados daqueles setores para esses. A indústria do país volta-se para dentro, especializando-se na produção de bens não comercializáveis que apresentam maior rentabilidade por conta da apreciação cambial. Evidências empíricas sobre o assunto podem ser encontradas em Bresser-Pereira e Marconi (2008).

Associando as duas teorias, Bresser-Pereira (2009 e 2010) argumenta que existe uma tendência estrutural à sobreapreciação cíclica da taxa de câmbio nos países em desenvolvimento, causada principalmente pela doença holandesa e a política de crescimento com poupança externa, de forma que não havendo qualquer intervenção de política cambial, não é o mercado mas crises recorrentes de balanço de pagamento que controlam a taxa de câmbio desses países.

\section{PRINCIPAIS FATOS ESTILIZADOS DO CASO BRASILEIRO}

a. Forte queda da participação da indústria de transformação no PIB, entre 1980 e 2008

O Gráfico 1 mostra as evoluções conjuntas da participação da indústria de transformação no produto total da economia brasileira (valor adicionado industrial 
/ PIB a preços básicos) e da taxa de câmbio efetiva real, em índices dos valores. Pode-se constatar a existência de dois diferentes padrões de evolução das séries e também o fato de a apreciação cambial estar associada a uma perda de mais de $50 \%$ da participação do valor adicionado industrial, no período 1980-19981.

Observe-se que a queda relativa do valor adicionado (VA) industrial tem início no período pré-abertura, quando, paralelamente, a taxa de crescimento da indústria não pode ser atribuída ao processo normal de desenvolvimento econômico, onde, no longo prazo, o setor serviços avança com consequente redução da participação relativa do setor industrial e agrícola. Até o ano de 1993, a participação relativa da indústria de transformação e a taxa de câmbio compartilhavam uma tendência comum de evolução, sugerindo a possibilidade de essas séries serem cointegradas. A partir de 1994, essas variáveis se desconectam, exibindo outro padrão muito diferente de evolução onde a participação do VA da indústria no PIB se mostra pouco sensível ao regime cambial vigente. Além disso, deve ser destacado que, no segundo período 1994-2007, caracterizado pela liberalização comercial e financeira e pelas transformações estruturais subsequentes, esta participação representa apenas metade do valor observado em 1980. Um sinal que aponta para a ocorrência de um processo de desindustrialização relativa da economia brasileira pós-abertura e pós-Real.

Gráfico 1: Taxa de Câmbio Efetiva Real e Participação da Indústria de Transformação no PIB

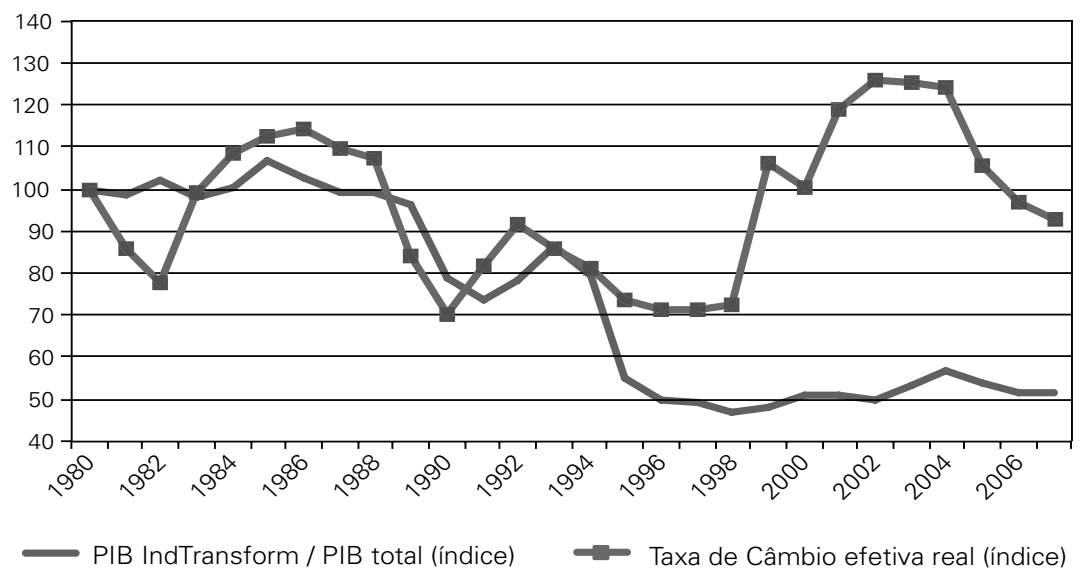

FONTE: IPEADATA (2009).

Uma possível explicação pode ser obtida considerando-se a ocorrência de mudanças estruturais na indústria, desencadeadas pela nova forma de inserção internacional da economia brasileira. No período 1980-1993, a configuração da indústria de transformação ainda refletia as estruturas de produção consolidadas ao longo do processo de substituição de importações e, portanto, do modelo econô-

\footnotetext{
${ }^{1}$ Precisamente, uma queda de $53,37 \%$.
} 
mico e das políticas de desenvolvimento industrial correspondentes. O regime cambial, combinado com políticas setoriais, fora mobilizado como uma das instituições-chave para a formação de capacidade produtiva no setor industrial. Mas a opção brasileira por uma nova forma de adesão ao regime internacional sem uma política industrial consistente vai acarretar transformações profundas no parque industrial, deslocando parte significativa dos ramos que produziam bens com maior intensidade tecnológica e valor agregado. Tais ramos certamente teriam contribuído para reduzir a elevada participação das commodities na pauta de exportações e, portanto, para reduzir a vulnerabilidade externa da economia brasileira em sua fase de adesão ao processo de globalização.

\section{b. Forte crescimento da intensidade do capital e da produtividade no período pós-liberalização}

A produtividade do trabalho (PRn) depende tanto da intensidade do capital $(\mathrm{K} / \mathrm{N})$ quanto da produtividade do capital fixo (VAIND/N), de modo que $P R n=\frac{V A I N D}{N}=\left(\frac{K}{N}\right)\left(\frac{V A I N D}{K}\right)$, onde VAIND, N e K são, respectivamente, o valor adicionado, o nível de emprego e o estoque de capital fixo em máquinas, equipamentos e infra estrutura no setor industrial. Esta decomposição mostra que os ganhos de produtividade do trabalho dependem do ritmo de substituição de trabalho por capital fixo e não apenas da produtividade do capital (VAIND/K). Mais precisamente, a razão K/N pode estar crescendo mantendo-se a mesma tecnologia, sendo um indicador sensível ao capital em volume. Mas a razão VAIND/K é sensível ao conteúdo tecnológico incorporado ao estoque de capital, pois o incremento em volume de $\mathrm{K}$ tende a reduzir os ganhos de produtividade do capital.

Gráfico 2: Produtividade da Indústria de Transformação e Intensidade do Capital (1982-2008)

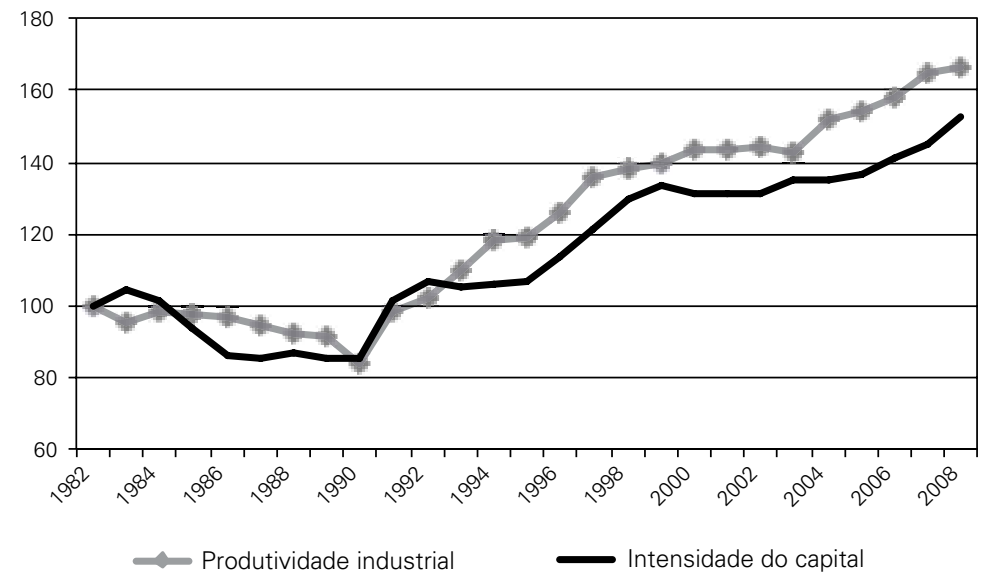

FONTE: PIM-PF/IBGE E IPEADATA.

NOTA: Para a estimativa da intensidade do capital na indústria de transformação, foi utilizada como proxy a razão entre o estoque de capital fixo em máquinas e equipamentos e o nível de emprego neste setor. 
O Gráfico 2 mostra que o período pós-1990 se caracteriza por ganhos crescentes de produtividade que estão associados à elevação da intensidade do capital. Destaca-se, contudo uma fase intermediária de estagnação entre 1999-2003. No período 2004-2008, marcado pela retomada do crescimento econômico brasileiro, observa-se um nítido deslocamento para cima da curva de produtividade com relação à curva da intensidade do capital, fato que deve estar associado à modernização de plantas e à redução dos custos de importação de bens de produção decorrente da apreciação cambial. Este fato pode parecer paradoxal, considerando-se que, no período 2004-2008, a indústria de transformação tem seu potencial produtivo aumentado, enquanto declina sua participação no PIB. Como explicar este fato estilizado?

Segundo Kaldor (1961, apud Arrous, 1999), o progresso técnico mensurado pela dinâmica dos ganhos de produtividade $(\mathrm{Y} / \mathrm{N})$ depende da taxa de acumulação de capital ou seja, do crescimento do estoque de capital fixo produtivo. Para representar graficamente a função de progresso técnico, distingue-se entre a posição e a forma da curva correspondente. A posição desta curva é obtida supondo-se que certos acréscimos de produtividade poderiam existir mesmo se o capital por trabalhador permanecesse constante. Por exemplo, há um certo número de inovações e de melhorias organizacionais que permitem elevar a produção sem investimento suplementar. Com relação à forma da curva, o crescimento da produtividade vai depender da taxa de crescimento do estoque de capital, com a curva sendo crescente a uma taxa decrescente. A Figura 1 ilustra a FPT teórica.

Figura 1: A Função de Progresso Técnico de Kaldor

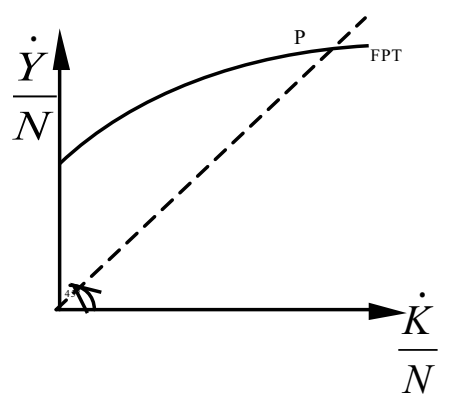

Em termos globais, esta curva reflete o grau de dinamismo técnico da economia no sentido amplo. Nos períodos onde se observam inovações técnicas e organizacionais, a curva é deslocada para cima. E no caso de fraca absorção de progresso técnico, move-se para baixo. Sua convexidade traduz, em cada ponto, em que medida um investimento engendra ganhos de produtividade. Até um certo ponto $\mathrm{P}$, de interseção da curva de progresso técnico com a reta de $45^{\circ}$, a taxa de crescimento da produtividade é maior do que a taxa de acumulação de capital. Neste caso, variações na taxa de lucro da indústria impulsionarão a taxa de acumulação em direção a P, através de novos investimentos. Além de $\mathrm{P}$, a taxa de acumulação supera a taxa de crescimento da produtividade, configurando um padrão de rendi- 
mento decrescente ${ }^{2}$. No ponto $\mathrm{P}$, a razão capital/produto (K/PIB) é constante, pois o produto e o estoque de capital fixo teriam a mesma taxa de crescimento. $\mathrm{O}$ Gráfico 3 é um scatter plot dessas séries, e proporciona uma representação empírica da função de progresso técnico kadoriana (FPT), para o caso da indústria no Brasil.

Gráfico 3: Duas FPT para a Indústria de Transformação (1982-2008)

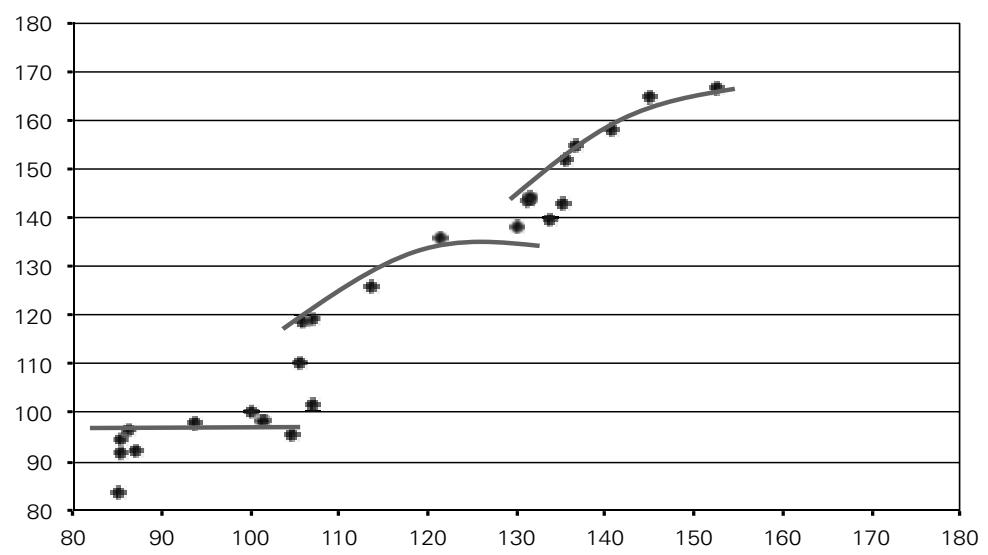

FONTE: Elaboração própria a partir de dados do IPEADATA: para o estoque líquido de capital fixo produtivo; e do IBGE: para a produtividade e emprego na indústria.

Observa-se que há duas curvas FPT(1) e FPT(2), mostrando que, entre 1993 e 2008, a expansão dos ganhos de produtividade ocorreu à medida em que a intensidade do capital se aprofundava. Este fato é mais um dos elementos que confirmam o processo de reestruturação deste setor, a partir da opção por uma nova forma de inserção internacional. Destaque-se que a curva FPT(2), vigente no período de recuperação do crescimento econômico brasileiro (2004-2008), é mais alta do que a curva FPT(1), tal como previsto pelos fundamentos teóricos propostos por Kaldor.

\section{c. Existência de retornos crescentes dinâmicos de escala no período 2003-2008}

O Gráfico 4 apresenta a evolução da produtividade horária, do nível de utilização da capacidade produtiva instalada (NUCI) e da razão produção física / Nuci. Esta última pode ser interpretada como uma medida do produto máximo desejado pelas firmas industriais. Trata-se do produto potencial da indústria de transformação, compreendido como aquele que assegura a rentabilidade máxima esperada, e não o máximo em termos de capacidade técnica de produção. Observe-

\footnotetext{
${ }^{2}$ Conforme GAFFARD (1997, p. 186), isto decorreria de um tipo de lei de rendimentos decrescentes cuja justificação permaneceria estritamente formal, isto é, a demonstração da existência de um equilíbrio, neste caso, no ponto $\mathrm{P}$.
} 
-se ainda, a forte queda dessas variáveis em finais de 2008, um reflexo da propagação da crise americana.

Este gráfico mostra a evolução conjunta da produtividade, do Nuci e da produção industrial, no período 1992-2008. Destaca-se o fato de que no período 2004-2008, os ganhos de produtividade retomam uma trajetória de crescimento similar a do período 1992-1998. Todavia, a razão Produção/Nuci cresce de forma expressiva, além de se descolar das variações da taxa de utilização da capacidade, fato que aponta para a existência de retornos crescentes de escala dinâmicos, de acordo com a chamada Lei de Kaldor-Verdoorn. Esta última busca representar os efeitos do crescimento cumulativo, quando níveis mais elevados de demanda puxam a produtividade que por sua vez, puxa a demanda, através de efeito-renda e do efeito-acelerador sobre o investimento produtivo. Em outros termos, neste último período do gráfico, a produtividade é muito mais elástica às variações da taxa de utilização da capacidade do que nos períodos precedentes. Este fato mostra que os ganhos de produtividade não resultaram apenas de fatores microeconômicos ou centrados, eles foram impulsionados pelo elevado dinamismo da demanda interna.

Gráfico 4: Produção, Produtividade e Nível de Utilização da Capacidade (1992-2008)

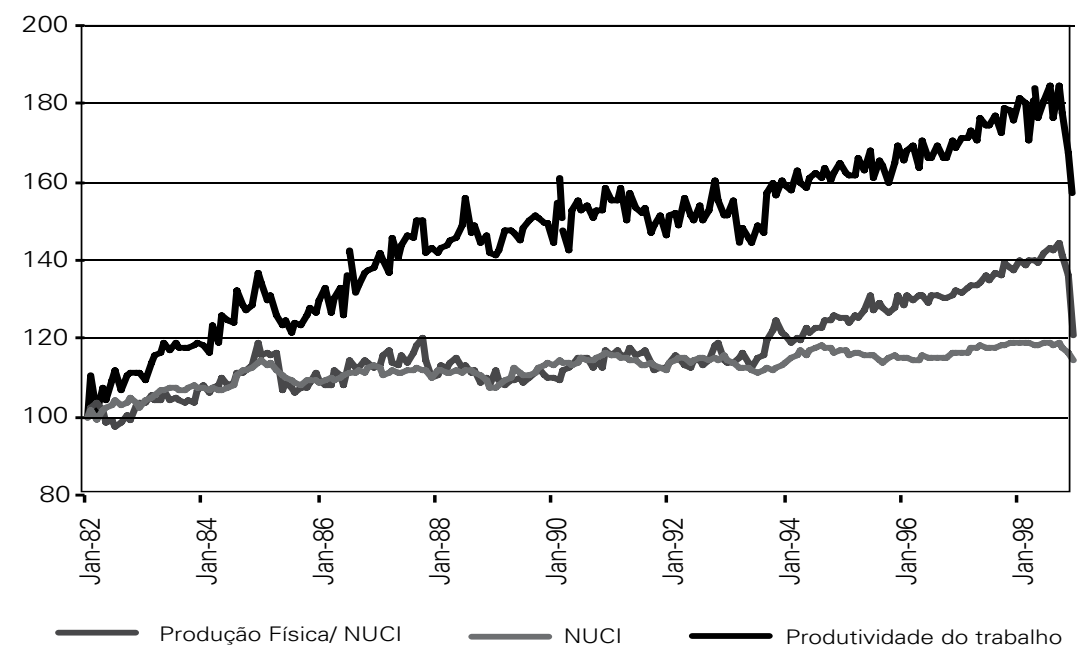

FONTE: Produtividade: PME antiga, até dez/2002; CNI, de jan/2003 a dez/2008; Nuci: CNI; PIM/IBGE: produção física da indústria de transformação; PIMES/IBGE: horas pagas.

\section{EVIDÊNCIAS DE NOVA ESTRUTURA INDUSTRIAL}

Uma análise de séries temporais entre câmbio e VA industrial

Como foi mencionado na seção anterior, o comportamento das séries do VA industrial / PIB e da taxa de câmbio efetiva real, pelo Gráfico 1, sugere a possibilidade de cointegração entre essas variáveis no período 1980-1993. No segun- 
do período, 1994-2007, o VA industrial / PIB permanece estagnado em um valor próximo à metade do observado em 1980, característica que irá se refletir no comércio exterior brasileiro, hoje fortemente dependente das exportações de commodities.

Foram aplicadas às séries da taxa de câmbio e do PIB da indústria de transformação, na periodicidade trimestral, o teste de quebra estrutural de Chow (1978), que possibilita investigar se em dois ou mais períodos existem diferenças significativas entre os parâmetros que estabelecem as relações entre as séries. Para exemplificar, suponha que a taxa de câmbio esteja correlacionada positivamente com o PIB da indústria de transformação em um período e negativamente em outro período, o teste indicará esta diferença de parâmetro e determinará a data de ocorrência da quebra estrutural. $\mathrm{O}$ resultado do teste indica o quarto trimestre de 1993 como o ponto de "quebra", assim, o período analisado pode ser dividido em duas subamostras, sendo a primeira de 1980:1 a 1993:3 e a segunda de 1993:4 a 2008:3.

O próximo passo é verificar se as séries PIB da indústria de transformação e taxa de câmbio compartilham uma trajetória comum de longo prazo, isto é, são cointegradas. Primeiramente, o teste de Dickey-Fuller Aumentado (ADF) indicou que as séries PIBIND (= VA industrial /PIB) e TXC (= taxa de câmbio efetiva real) são não estacionárias nas duas subamostras. Em seguida, o procedimento de Johansen $^{3}$, determinou o número de vetores de cointegração e o estimou (Tabela 1).

Tabela 1: Teste de Johansen

\begin{tabular}{lcccc}
\hline & \multicolumn{2}{c}{ Máximo Valor } & \multicolumn{2}{c}{ Estatística Traço } \\
\cline { 2 - 5 } & Valor Observado & Valor crítico 5\% & Valor Observado & Valor crítico 5\% \\
\hline$r=0$ & Amostra: 1980:1 a 1993:3 \\
$\mathrm{R} \leq 1$ & 4.302052 & 19.38704 & 28.19454 & 25.87211 \\
\hline $\mathrm{r}=0$ & 12.51798 & 4.302052 & 12.51798 \\
$\mathrm{R} \leq 1$ & 5.115637 & Amostra: 1993:4 a 2008:3 & \\
\hline
\end{tabular}

Fonte: Elaboração própria com base nos dados da pesquisa.

Nota: Incluíram-se os termos constante e tendência e estimou-se o modelo com 1 defasagem.

Considerando o nível de 5\% de significância, rejeita-se a hipótese nula de não cointegração e aceita-se a hipótese alternativa de que existe um vetor de cointegração entre as séries na primeira amostra. Já na segunda subamostra, os testes indicam que não existe cointegração entre as séries, ou seja, elas se movem de modo

\footnotetext{
${ }^{3}$ Uma apresentação mais completa do procedimento de Jonhansen pode ser encontrada em Enders (1995).
} 
independente. Esses resultados empíricos apontam para a ocorrência de transformações significativas na estrutura da indústria brasileira, no período de liberalização comercial e financeira pós-1994.

No primeiro período 1980-1993, a estrutura industrial mostrava-se altamente sensível ao regime de câmbio vigente. Esse comportamento pôde ser verificado pela existência de uma relação de longo prazo entre a participação do valor adicionado industrial no PIB e a taxa de câmbio efetiva real, dada pela cointegração entre essas duas variáveis.

Para verificar de forma mais aprofundada a relação entre câmbio e o VA da indústria calculou-se a sensibilidade do VA industrial em relação à taxa de câmbio, tanto no curto quanto no longo prazo. A Tabela 2 ilustra os resultados.

Tabela 2: Elasticidade do VA da indústria em relação ao câmbio

\begin{tabular}{l|c|c}
\hline & $1980: 1-1993: 3$ & $1993: 4-2008: 3$ \\
\hline Elasticidade de curto prazo & 0.1414 & -0.0181 \\
& $(2.8309)$ & $(-0.7217)$ \\
Elasticidade de longo prazo & 0.3374 & Sem cointegração \\
& $(2.8385)$ & $\downarrow$ \\
\hline
\end{tabular}

Fonte: Elaboração própria com base nos dados da pesquisa. Nota: teste t entre parênteses

Como na primeira subamostra as variáveis possuem uma raiz unitária e são cointegradas, o método de Mínimos Quadrados Ordinários (MQO) continua sendo eficiente quando aplicado às séries em nível. Assim, a elasticidade de curto prazo é calculada pelo método de MQO e a de longo prazo pelo modelo de Vetores de Correção de Erros (VEC). Em ambos os modelos a sensibilidade do VA da indústria em relação ao câmbio é positiva e significativa, mostrando que a indústria respondia positivamente a desvalorizações da taxa de câmbio. No longo prazo, o aumento de $10 \%$ na taxa de câmbio provoca o aumento de $3,3 \%$ no VA da indústria, no curto prazo este aumento é de $1,4 \%$. Na segunda subamostra, a não existência de cointegração entre as duas séries inviabiliza o cálculo da elasticidade de longo prazo, como também o modelo de MQO precisa ser utilizado com as séries em primeira diferença. Neste segundo período, a sensibilidade do VA da indústria em relação ao câmbio deixa de ser significativa, o que confirma a hipótese de que a indústria que se manteve sob o processo de apreciação cambial não é mais sensível as mudanças na taxa de câmbio.

A interpretação do resultado da primeira fase pode partir do fato de que a indústria nesse período era composta por ramos que se constituíram sob a lógica e as incitações econômicas do modelo de industrialização por substituição de importações (MISI). Na vigência deste modelo, uma taxa de câmbio competitiva ou suficientemente depreciada era uma das macrovariáveis básicas para a manutenção de um ambiente macroeconômico favorável aos investimentos industriais. Mas na passagem para o segundo período, 1994-2008, a nova forma de inserção internacional do Brasil foi marcada por um processo acelerado de liberalização comercial e financeira, conjugado com uma forte apreciação da taxa de câmbio. 
Esse novo ambiente macroeconômico pós-abertura foi determinante para a retração ou o fechamento de diversas unidades produtivas industriais que se viram rapidamente expostas à concorrência internacional, sem o intercurso de uma política de desenvolvimento industrial consistente e adequada às necessidades do crescimento e do desenvolvimento econômico nacional. A hipótese sustentada por este trabalho é a de que o regime de câmbio apreciado foi prejudicial aos setores e ramos tecnologicamente mais sofisticados, favorecendo os ramos mais tradicionais e os ligados às atividades primárias. Esse regime mudou o perfil de especialização da indústria, provocando um processo de desindustrialização relativa da economia brasileira.

Neste caso, a indústria perde sua participação econômica antes mesmo de a economia ter alcançado seus estágios mais avançados de desenvolvimento. Esta desindustrialização tem como contrapartida uma expansão igualmente precoce do setor serviços ("inchaço do terciário") conduzindo, inclusive, à precarização do trabalho e a níveis mais elevados de informalidade, sendo portanto, um fator de bloqueio do processo de desenvolvimento econômico e social. Além disso, essa definição de desindustrialização não pode se basear apenas em indicadores de níveis de emprego, pois as atuais bases técnicas produtivas são intensivas em capital, característica que conduziria a uma queda do pessoal ocupado, podendo sinalizar, equivocadamente, para uma perda de participação da indústria no PIB.

Destaque-se que os ramos remanescentes do processo de desindustrialização da economia brasileira pós-liberalização são precisamente aqueles cuja performance é pouco afetada pelo atual regime de câmbio flutuante com forte tendência à apreciação. Consequentemente esta característica apontaria para a ocorrência de “doença holandesa". Segundo Pereira (2008), esse fenômeno conexo caracteriza-se pela expansão, em um país, da produção dos setores de bens comercializáveis, beneficiados por alguma vantagem comparativa natural (abundância e maior produtividade de recursos naturais, por exemplo) e o declínio relativo concomitante das atividades manufatureiras. Como sustentam Corden e Neary (1982) e Bresser-Pereira (2008), uma apreciação permanente da taxa de câmbio real deve estar associada a um aumento relativo do setor exportador de commodities, de maior produtividade, e a um encolhimento do setor manufatureiro.

\section{Uma análise por ramos da indústria de transformação}

Para analisar as eventuais mudanças ocorridas na estrutura interna da indústria de transformação a partir da liberalização econômica os diversos segmentos de atividades industriais foram classificados de acordo com o tipo de fator intensivo. A tipologia foi elaborada pela OECD inspirada em Pavitt (1984).

As Tabelas 3 e 4 apresentam o Valor da Transformação Industrial (VTI) segundo Pavitt (1984). O VTI é a diferença entre valor bruto da produção industrial e o custo das operações industriais. 
Tabela 3: Participação Percentual no Valor de Transformação da Indústria 1988 a 1995

\begin{tabular}{l|c|c|c|c|c|c|c}
\hline & 1988 & 1989 & 1990 & 1992 & 1993 & 1994 & 1995 \\
\hline Produção em escala & 44,27 & 43,40 & 43,23 & 46,37 & 45,69 & 46,71 & 47,00 \\
\hline Recursos Naturais & 22,44 & 21,67 & 21,80 & 24,92 & 24,11 & 24,85 & 26,25 \\
\hline Trabalho & 13,67 & 14,79 & 15,26 & 11,59 & 12,75 & 12,00 & 10,02 \\
\hline Ciência & 10,34 & 10,83 & 10,88 & 10,04 & 11,06 & 10,23 & 10,73 \\
\hline Diferenciado & 9,28 & 9,30 & 8,83 & 7,07 & 6,39 & 6,21 & 6,00 \\
\hline
\end{tabular}

Fonte: IBGE - Pesquisa Industrial Anual

Nota: Participação Percentual somente na indústria de transformação.

Analisando os dados das tabelas, pode-se verificar que as atividades que mais aumentaram a sua participação no valor da transformação industrial (VTI) foram as intensivas em recursos naturais, com um aumento de mais de 3 pontos percentuais na primeira série da PIA e de mais de 6 pontos na segunda série. A principal atividade deste grupo é a fabricação de produtos alimentícios, porém a atividade responsável por quase a totalidade do crescimento da sua participação foi a ligada ao refino de petróleo.

As atividades intensivas em escala são as que possuem maior participação no VTI em ambas as séries. Produtos químicos, metalurgia e veículos compõe a grande parte desse grupo que de forma geral manteve estável a sua participação na estrutura da produção industrial. Destaca-se a atividade metalúrgica, que apresenta queda na primeira série da PIA e recupera-se apresentando crescimento a partir de 1996.

Os outros três grupos de atividades perderam participação. O grupo intensivo em trabalho foi o que apresentou a maior perda de participação, de 3 pontos percentuais em cada série da PIA, com destaque negativo para a participação do setor têxtil e de vestuário.

Tabela 4: Participação Percentual no Valor de Transformação da Indústria - 1996 a 2005

\begin{tabular}{l|l|l|l|l|l|l|l|l|l|l}
\hline & 1996 & 1997 & 1998 & 1999 & 2000 & 2001 & 2002 & 2003 & 2004 & 2005 \\
\hline Produção em Escala & 36,79 & 38,27 & 37,97 & 37,34 & 36,26 & 35,03 & 36,04 & 37,12 & 39,16 & 37,22 \\
\hline Recursos Naturais & 33,77 & 33,22 & 34,00 & 36,27 & 37,67 & 37,98 & 38,85 & 40,17 & 37,58 & 39,71 \\
\hline Trabalho & 14,45 & 13,40 & 13,83 & 13,20 & 12,53 & 12,54 & 12,04 & 11,20 & 11,13 & 11,29 \\
\hline Diferenciado & 10,88 & 11,12 & 10,72 & 9,56 & 9,03 & 9,87 & 9,46 & 8,92 & 9,12 & 8,91 \\
\hline Ciência & 4,12 & 3,99 & 3,48 & 3,64 & 4,52 & 4,58 & 3,61 & 2,59 & 3,01 & 2,87 \\
\hline
\end{tabular}

Fonte: IBGE - Pesquisa Industrial Anual

Nota: Participação Percentual somente na indústria de transformação.

O grupo intensivo em produtos diferenciados tem uma queda de participação muito significativa no período. Esse setor é representado pelas atividades de produção de máquinas e equipamentos e sofreu com o forte impacto da abertura comercial e da valorização cambial do período que provocou grande aumento na importação desses itens. Da mesma forma impactou a produção dos setores baseadas em ciência responsáveis pela produção de eletrônicos e de informática. 
Portanto, considerando-se os dados apresentados referentes a participação das atividades industriais em relação ao valor da transformação industrial, pode-se constatar que ocorreu no período após a liberalização da economia uma especialização produtiva da indústria com ênfase em setores intensivos em recursos naturais. Enquanto que setores tradicionais como têxteis e vestuário, e atividades ligadas à produção de máquinas e equipamentos perderam importância relativa. Estes setores foram fortemente impactados pelo grande aumento do nível das importações após a abertura comercial.

Neste ponto cabe ressaltar que a especialização ocorrida na indústria de transformação brasileira coincide com o período de valorização cambial. Como se sabe, a taxa de câmbio valorizada torna os produtos nacionais mais caros no exterior, ao passo que os produtos externos tornam-se mais barato no país. Isso contribui para estimular a importação de insumos industriais, aumentando o componente importado da indústria nacional, como também torna os produtos nacionais menos competitivos no exterior. Somente aqueles produtos nos quais o país possui uma grande vantagem de custo tornam-se viáveis com o câmbio sobrevalorizado, de modo que apenas os setores de commodities vêm se destacando em termos de participação na indústria e em termos de crescimento.

\section{Os efeitos do câmbio sobre o comércio exterior ${ }^{4}$}

Os efeitos do câmbio sobre a indústria têm repercussão direta no comércio exterior brasileiro, tanto sobre o saldo dos diferentes setores exportadores, como sobre a intensidade téconologica das exportações da indústria brasileira.

É sabido que a composição da balança comercial é o principal indicador de competitividade de uma economia, no entanto, como será mostrado mais adiante, as exportações brasileiras vêm se concentrando em commodities e bens de menor valor agregado. Apesar de o Brasil exportar predominantemente produtos industrializados, seus principais produtos são commodities ou bens de pouca intensidade tecnológica.

$\mathrm{Na}$ Tabela 5 é possível verificar a dependência do saldo comercial brasileiro (SBC) em relação ao setor de commodities. Os resultados evidenciam a importância da capacidade geradora de saldos comerciais dos setores agrícolas, com destaque para o setor de cereais, produtos animais e agricultura tropical. Quanto aos setores deficitários, destaca-se o setor de química e de máquinas (eletroeletrônicas e demais). Tanto os setores exportadores tradicionais têm mantido sua capacidade de gerar saldos comerciais, como os setores tradicionalmente deficitários mantêm-se dessa maneira e, ainda, estes últimos aumentam sensivelmente sua participação negativa no saldo comercial

\footnotetext{
${ }^{4}$ Os dados desta seção baseiam-se no estudo sobre o comércio exterior realizado pelo Instituto de Estudos para o Desenvolvimento da Indústria (IEDI), 2009.
} 
Tabela 5: Saldo Comercial em US\$ bilhões

\begin{tabular}{l|cccccc}
\hline & 2003 & 2004 & 2005 & 2006 & 2007 & 2008 \\
\hline Petróleo & -2.0 & -4.6 & -3.7 & -3.1 & -5.1 & -8.2 \\
Mat. Primas & 3.0 & 3.8 & 6.4 & 7.8 & 9.2 & 10.5 \\
Prod. Florestais & 4.3 & 5.1 & 5.5 & 5.9 & 6.6 & 6.7 \\
Agricultura tropical & 5.4 & 6.2 & 8.4 & 11.2 & 11.2 & 11.7 \\
Produtos animais & 4.3 & 6.4 & 8.3 & 8.6 & 11.4 & 14.8 \\
Cereais & 7.9 & 11.4 & 10.8 & 10.4 & 13.9 & 20.2 \\
Int. em trabalho & 4.1 & 5.0 & 5.7 & 5.8 & 5.4 & 5.7 \\
Int. em capital & 6.1 & 8.1 & 9.8 & 9.5 & 9.0 & 8.7 \\
Maq. Eletroeletrônic. & -4.1 & -6.5 & -6.8 & -9.1 & -12 & -17.4 \\
Maq. e veículos rodoviários & 3.2 & 4.8 & 6.8 & 6.2 & 4.5 & 1.1 \\
Máq. e outros transporte & 1.4 & 3.6 & 2.6 & 2.2 & 3.9 & 4.2 \\
Máq. Demais & -2.9 & -1.9 & -1.9 & -2.6 & -6.6 & -12.9 \\
Química & -6.1 & -8.1 & -7.3 & -7.2 & -12.2 & -21.4 \\
\hline
\end{tabular}

Fonte: IEDI (2009)

A respeito do desempenho do SBC, o IEDI (2009) chama a atenção para dois aspectos fundamentais. O primeiro deles, é que existe uma crescente relação de antagonismo entre os diferentes segmentos do comércio exterior brasileiro, isto é, existem, por um lado, segmentos claramente superavitários e, por outro, aqueles com resultados extremamente negativos. $\mathrm{O}$ segundo aspecto, que está relacionado ao primeiro, se refere ao fato de que o SBC do país depende cada vez mais de bens de baixo valor agregado, pouco ou não industrializados, cujos empregos gerados exigem baixa qualificação.

O IEDI conclui que este aspecto pode não se configurar como um problema para os defensores da Teoria das Vantagens Comparativas ou correlatas, isto é, da ideia de que cada país deve se especializar nos produtos que possuem menores custos relativos de produção, mas certamente é algo negativo para os que argumentam a favor de um projeto para o Brasil que passa pela industrialização (IEDI, 2009).

Outro ponto relevante é investigar a intensidade tecnológica dos produtos exportados pela indústria brasileira ${ }^{5}$. A Tabela 6 aponta dados do saldo comercial da indústria de transformações no Brasil.

\footnotetext{
${ }^{5}$ Para isso, o IEDI (2009) utilizou certas categorias de agregações por intensidade tecnológica da indústria de transformação. O critério de conteúdo tecnológicos segundo a OCDE, discrimina os setores de alta, média alta, média baixa e baixa intensidade tecnológica.
} 
Tabela 6: Balança Comercial da Indústria de Transformação em US\$ bilhões

\begin{tabular}{l|cccccc}
\hline & 2003 & 2004 & 2005 & 2006 & 2007 & 2008 \\
\hline Baixa & 19.856 & 25.197 & 28.727 & 31.927 & 34.761 & 39.559 \\
Média baixa & 5.488 & 8.871 & 10.258 & 10.545 & 9.185 & 5.118 \\
Média alta & -3.376 & -2.531 & 443 & -897 & -10.344 & -30.190 \\
Alta & -5.245 & -7.484 & -8.320 & -11.779 & -14.824 & -21.653 \\
Prods. Ind. transformação & 16.723 & 24.053 & 31.107 & 29.796 & 18.779 & -7.166 \\
\hline
\end{tabular}

Fonte: IEDI (2009)

Observa-se pela Tabela 6, que o setor mais importante na geração de saldo comercial para o Brasil, considerando o conteúdo tecnológico, é o de baixo conteúdo, seguido pelo segmento médio baixo, mas com um resultado consideravelmente menor. O IEDI (2009) aponta que os subsetores alimentos, bebidas e tabaco, foram responsáveis sozinhos por 78,8\% do saldo gerado pelo setor em 2008.

Pelo lado dos setores deficitários, alta e média alta intensidade tecnológica, os dois vêm apresentando saldos comerciais negativos ou muito próximos a zero durante todos os períodos analisados. Chama atenção o montante do déficit gerado pelo segmento de média alta intensidade (US\$ -30,2 bilhões em 2008). Por fim, o segmento de alta tecnologia, em 2008, atingiu um déficit de US\$ -21,7 bilhões.

No que diz respeito ao saldo comercial brasileiro gerado pela indústria de transformação, este, que apresentou uma trajetória claramente ascendente entre os anos de 2003 e 2005, tal como indica o Gráfico 5, em 2006 essa trajetória foi revertida e, em 2008 o déficit deste setor foi de US\$ 7,2 bilhões.

Gráfico 5: Balança Comercial em US\$ bilhões

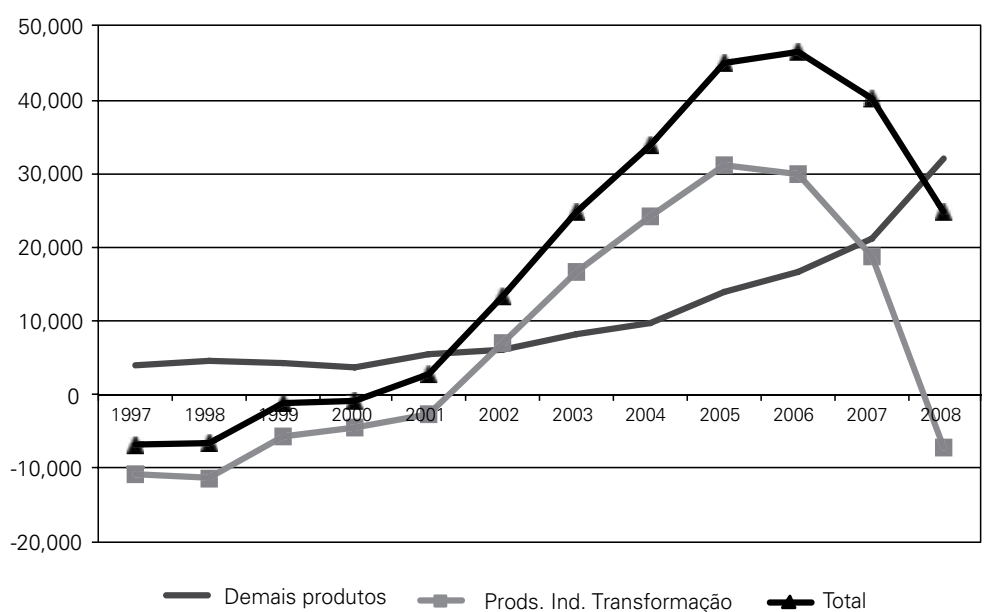

Fonte: IEDI (2009) 
Cabe notar que houve uma queda substancial do resultado externo determinada pelo desempenho negativo da indústria de transformação, destacando-se que o último déficit registrado foi em 2001.

A este respeito, a conclusão é que o Brasil permanece, portanto, dependente, no que tange à geração de saldos comerciais dentro da indústria de transformação, de produtos com baixa e média baixa intensidade tecnológica. Enquanto os setores de alta e média alta tecnologia são grandes importadores e os maiores geradores de déficits. Além disso, é preciso apontar que após diversos anos de importantes superávits a indústria de transformação volta a gerar um déficit significativo. Além da concentração do saldo comercial do país em bens pouco industrializados, existe também uma concentração das exportações em bens de baixa tecnologia e das importações em produtos com alta intensidade tecnológica.

\section{CONCLUSÃO: DESINDUSTRIALIZAÇÃO E/OU REESPECIALIZAÇÃO PRODUTIVA}

A análise dos efeitos do regime cambial sobre as mudanças na estrutura da indústria de transformação mostra que a forte queda da participação do valor adicionado industrial no PIB brasileiro pode ser explicada pela tendência de apreciação real do câmbio, entre 1980 e 1993. Este fato deve, porém, ser mais bem qualificado com respeito às especificidades da estrutura industrial pré-liberalização. As plantas então estabelecidas sob as políticas econômica e industrial associadas ao modelo de industrialização substitutiva de importações pressupunham um elevado grau de proteção inerente a esse tipo de estratégia de desenvolvimento. Todavia, sem haver completado seu processo de industrialização, o Brasil se reinsere no cenário internacional com fortes desvantagens competitivas em setores estratégicos como o intensivo em ciências e em tecnologia. Sujeito, no plano interno, a um ambiente macroeconômico adverso (taxas muito altas de juros, ausência de políticas industriais e setoriais consistentes, déficit em infraestrutura de transportes etc.), a reação do parque produtivo doméstico foi então nitidamente defensiva, orientando-se pela sobrevivência diante das incertezas crescentes.

Entre 1980 e 1996, a indústria de transformação tem reduzida em $50 \%$ a sua participação no produto interno bruto. Um dos fatores principais dessa evolução foi a forte apreciação cambial iniciada no período pré-abertura. Mas a despeito da agenda liberalizante, essa perda não foi recuperada no período 1997-2008 quando a economia brasileira consolida sua adesão ao processo de globalização comercial e financeira. Pelo contrário, apesar da modernização das plantas, favorecida pela importação de bens de capital e dos elevados ganhos de produtividade, a indústria continuou perdendo participação relativa entre 2004 e 2008, precisamente quando a economia brasileira crescia a taxas mais altas. Pesquisas futuras são necessárias para detectar as razões econômicas por trás desse comportamento. A opção por trajetórias de acumulação intensiva pode ser parte importante da explicação, mas 
sobressai-se também o fato de que a indústria que sobreviveu à apreciação cambial é basicamente produtora de bens de mais baixo valor agregado.

Análises históricas e comparações internacionais mostram que as mudanças nas formas de inserção internacional são decisivas na reconfiguração da indústria e, mais amplamente, do próprio ambiente econômico doméstico. Afastando-se das concepções mais otimistas da tradição liberal-neoclássica, não há fundamento teórico nem empírico satisfatórios que possam corroborar as interpretações de que os processos de liberalização econômica são sempre portadores de benesses e de vantagens econômicas irrecusáveis. As experiências dos países asiáticos confirmam que o recurso a uma estratégia consistente de desenvolvimento com políticas industriais adequadas é uma condição necessária para que os desafios impostos pela concorrência internacional possam se converter em fatores propulsores do desenvolvimento das nações. A mera adesão a um ambiente externo de alta concorrência pode acarretar perdas em setores e ramos importantes da indústria nacional. Políticas proativas de desenvolvimento industrial devem ser o recurso básico para o enfrentamento da concorrência externa e para a aquisição de vantagens competitivas dinâmicas.

\section{REFERÊNCIAS BIBLIOGRÁFICAS}

ARROUS, J. (1999). Les théories de la croissance. Economie. Éditions du Seuil, février.

ATELLA, V.; ATZENI, G. E.; and BELVISI, P. E. (2003). Investment and exchange rate uncertainty. Journal of Policy Modeling 25, 811-824.

BLECKER, R. A. (2005).The Economic Consequences of Dollar Appreciation for US Manufacturing Investment: A Time-Series Analysis. American University, Massachusetts.

BONELLI, R.; GONÇALVES, R. (1998). "Para onde vai a estrutura industrial brasileira?” TD IPEA 540.

BRESSER-PEREIRA, L. C. (2010). A tendência à sobreapreciação da taxa de câmbio no Brasil, em Luiz Carlos Bresser-Pereira, org. Crise Global e o Brasil, Rio de Janeiro: Editora da Fundação Getulio Vargas.

BRESSER-PEREIRA, L. C. (2009). A tendência à sobreapreciação da taxa de câmbio. Econômica 11 (1), junho: 7-30. Texto para Discussão EESP/Fundação Getulio Vargas 183, março 2009.

BRESSER-PEREIRA, L. C. e MARCONI, N. (2008). Existe doença holandesa no Brasil?”, in Bresser-Pereira org. (2008) Doença Holandesa e Indústria. Rio de Janeiro: Editora da Fundação Getulio Vargas: 207-230.

BRESSER-PEREIRA, L. C. (2008). "Dutch disease and its neutralization: a Ricardian approach", Revista de Economia Política 28 (1) janeiro-março 2008: 47-71.

BRESSER-PEREIRA, L. C. (2007). Macroeconomia da estagnação: crítica da ortodoxia convencional no Brasil pós-1994, Editora 34, São Paulo.

BRESSER-PEREIRA, L.,C. e Y. NAKANO (2003). “Crescimento com poupança externa?” in Revista de Economia Política, vol. 23, n.2, abril-junho: 3-27.

BYRNE, J. P. and DAVIS, E. P. (2005). The Impact of Short- and Long-run Exchange Rate Uncertainty on Investment: A Panel Study of Industrial Countries. Oxford Bulletin Of Economics and Statistics, 67.

CAMPA, J., GOLDBERG, L. S. (1995). Investment in manufacturing, exchange rates and external exposure, Journal of International Economics, 38(3/4), May, pp. 297-320.

CAMPA, J. M., GOLDBERG, L. S. (1999). Investment, pass-through, and exchange rates: a crosscountry comparison, International Economic Review, 40(2), May, pp. 287-314. 
CARVALHO, L. e KUPFER, D. (2008a). A Transição Estrutural da Indústria Brasileira: da Diversificação para a Especialização. Texto apresentado na $12^{\text {th }}$ Schumpeter Society Conference, UFRJ, Julho de 2008.

CARVALHO, L. e KUPFER, D. (2008b). A transição estrutural da indústria brasileira: uma análise dos fatores explicativos pela ótica da demanda. XXXVI Encontro Nacional de Economia da ANPEC, 2008.

CORDEN, W. Max e J. Peter Neary. (1982). "Booming Sector and De-Industrialisation in a Small Open Economy”, The Economic Journal, Vol. 92, No. 368, pp. 825-848.

DARBY, J., HUGHES HALLETT, A., Ireland, J. and Piscatelli, L. (1999). 'The impact of exchange rate uncertainty on the level of investment', Economic Journal, Vol. 109, pp. C55-C67.

DARBY, J., HUGHES HALLETT, A., Ireland, J. and Piscatelli, L. (2002). Exchange Rate Uncertainty, Price Misalignments and Business Sector Investment, University of Strathclyde, Mimeo.

ENDERS, W. (1995). Applied econometric time series. John Wiley \& Sons.

FERRAZ, J.C., KUPFER, D. e IOOTTY, M. (2004). "Competitividad industrial em Brasil: 10 años después da la liberalización”. Revista de la CEPAL 82, abril 2004.

GAFFARD, Jean-Luc. (1997). Croissance et fluctuations économiques. $2^{a}$ Édition. Montchrestien. Paris, 1997.

GARCIA, C. (2004). A Configuração da Indústria Brasileira no Período 1985-2000. IX Encontro Nacional de Economia Política - Uberlândia: Instituto de Economia - UFU, 2004. v. Único. p. 78-78.

GOLDBERG, L. S. (1993). Exchange rates and investment in United States industry, Review of Economics and Statistics, 75(4), November, pp. 575-588.

HARCHAOUI, T.; TARKHANI, F. and YUEN, T. (2005). The Effects of the Exchange Rate on Investment: Evidence from Canadian Manufacturing Industries. Working Paper 2005-22.

IBGE - Instituto Brasileiro de Geografia e Estatística (2008). Pesquisa Industrial Anual (PIA).

IEDI - Instituto de Estudos para o Desenvolvimento Industrial (2009). Os resultados de 2008 e os Primeiros impactos da crise sobre O comércio exterior brasileiro. IMBS, J. e R. WACZIARG. 2003. "Stages of diversification". American Economic Review, 93(1):63-86.

IPEADATA - Instituto de Pesquisa Econômica Aplicada (2009). Disponível em: <http://www.ipeadata. gov.br>.

KUPFER, D. (2003). "Política Industrial”. Econômica: revista da Pós-Graduação em Economia da UFF, Rio de Janeiro, v.5, n.2, p.281-298, dez. 2003.

PAVITT, Keith. (1984). Sectoral Patterns of technical change: towards a taxonomy and a Theory. Research Policy 13, p 343-373.

PEREIRA, E. (2008). Taxa de Câmbio e Mudança Estrutural da Indústria Brasileira. V Fórum de SP.

NUCCI, F. and POZZOLO, A. F. (2001). Investment and the exchange rate: An analysis with firm-level panel data. European Economic Review 45 259-283.

WORTHINGTON, P. R. (1991). Investment, GNP, and real exchange rates, Economic Perspectives (Federal Reserve Bank of Chicago), 15(4), July/August, pp. 2-10. 